\title{
Assessment of Knowledge of Diabetic Patients about Glycemic Abnormalities and Medicine Storage in Makkah during Hajj Pilgrimage
}

\author{
Kolthoom Othman', Aejaz Abdul Latif Khan', Syed Mohammad Shakeel lqubal', Tasneem \\ Mohammed ${ }^{1}$, Muazzam Sheriff Maqbul', Mohammed Gamal'2, Mohammad Mahmoud Al-Sanea ${ }^{2}$, \\ Mohammed Elmowafy ${ }^{2}$, Khaled Shalaby², Dibya Sundar Panda ${ }^{2, \star}$, Saleh Alghamdi ${ }^{3}$
}

${ }^{1}$ Department of Pharmacy, Ibn Sina National College for Medical Studies, Jeddah, KSA.

${ }^{2}$ College of Pharmacy, Jouf University, Sakaka, KSA.

${ }^{3}$ Department of Clinical Pharmacy, Faculty of Clinical Pharmacy, Al baha University, Al baha, Saudi Arabia.

\begin{abstract}
Objectives: The main objective of this research was to evaluate the awareness about symptoms of diabetes and dealing with those symptoms, management and storage of drug especially for the heat sensitive hormone (insulin) by diabetic patients participating in Hajj and the residents of Makkah. Methods: This cross-sectional study was conducted for diabetic patients participating in Hajj and the residents of Makkah. The sample was composed of 459 diabetic patients, typed questionnaires were administered with an interview, electronic and verbal interview was conducted on 104 patients ( 50 patients in holy place Al-Mashaeer adjacent to Makkah and 40 in the hospital), while the electronic one was conducted on 355 diabetics residing in Makah. Results and Conclusion: About $94 \%$ of participants of the study "Sample Makkah" store their insulin in a cool place, while $6 \%$ of them don't. $37.7 \%$ of participants of the study "Sample Makkah" have mobile cooling box, while $62.3 \%$ are without any facility for storage. $49.4 \%$ of participants of the study "Sample Makkah" check blood sugar before taking the dose of insulin, while $50.4 \%$ of them don't. There are no differences between Makkah and Hajjaj pilgrims regarding storage of insulin, following healthy diet and awareness about the symptoms of low blood sugar. While, there is a difference in knowledge to deal with low blood sugar symptoms between diabetic patients of Makkah and Hajjaj pilgrims. Also there is no suitable place (refrigerator) for storing insulin and no mobile coolers to suit their move through Al-Mashaeer (holy place). The diabetics don't do blood sugar test regularly. Health care sector should educate pilgrims about the importance of having healthy food and should conduct training sessions for the diabetics to increase awareness about dealing with their chronic diseases, educational leaflets about dealing with low or high blood sugar should be distributed.
\end{abstract}

Key words: Hajj, Diabetics, Storage, Insulin, Awareness.

\section{INTRODUCTION}

Hajj is a great Islamic gathering in which more than two millions of people come to Makkah every year. ${ }^{1}$ Some of these people are in advancing age and may be suffering from diabetes mellitus as chronic disease, ${ }^{1}$ management of diabetic significantly depends on a stable routine. ${ }^{2}$ Along with continuous management and proper storage of its medications (insulin) also very important. ${ }^{1}$ The temperature in Makkah and
Masher areas may be exceeding $40^{\circ} \mathrm{C}$ which may affect the stability of the medications requiring storage in refrigerator. ${ }^{3}$ Lack of sufficient insulin/medications with uncontrolled diet may precipitate high glucose level leading to complications such as diabetic ketoacidosis or hyperglycemic hyperosmolar state. ${ }^{3}$ Episodes of hypoglycemia are common during Hajj and associated with risk factors such as excessive
Submission Date: 06-12-2019; Revision Date: 20-04-2020; Accepted Date: 17-08-2020

DOI: 10.5530/ijper.54.3s.172 Correspondence:

Dr. Dibya sundar panda College of Pharmacy, Jouf University, Sakaka-72345, KSA.

Phone: +966-12-591402781 E-mail: dibyapanda1974@ gmail.com

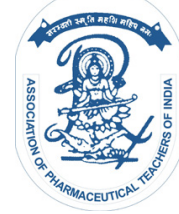

www.ijper.org 
physical activities, irregular and small meals, predilection for rendering prayers in the holy places, increase in temperature during summer seasons may induce insulin absorption to produce lowering of glucose level and it may conversely interfere with the cause of increased blood glucose level and storage of insulin. ${ }^{2}$ Patients who use twice daily high doses of soluble insulin with no intermediate insulin with physical exercise or delayed meal could suffer from hypoglycemia. ${ }^{2}$ The others may have hypoglycemic episodes with unknown cause, generally the optimal doses of insulin during a routine lifestyle prove excessive during Hajj, due to their moderate to excessive efforts in that period. ${ }^{2}$ High placed, hard excessive exhaustion, withdrawal of insulin or oral hypoglycemic medication, inanition, sepsis and alcohol use were recorded as factors leading hyperglycemic and diabetic ketoacidosis. Therefore, there is a badly need for institution of a special health education program to all the Hajjis before taking the endeavor. ${ }^{4}$ A study was done from 2007-2009 on five thousand nine hundred and eighty-three diabetes patients to evaluate health care services provided to patients suffering from diabetes and expenditure on diabetes health care in Saudi Arabia. ${ }^{5}$ Almost 92.2 percent of medical services were governmental and others were in private services. ${ }^{5}$ Another study reveals that diabetes patients get hospitalized once in every 3 years with a mean stay duration $13.3 \pm 28.3$ days. ${ }^{5} 85.9 \%$ of diabetic cases were managed by general practitioner alone, or with internists and/or endocrinologists. ${ }^{5}$ There is badly need to empower the role of the private sector and health insurance system, in implementing a perfect management guidelines to provide excellent services at different levels. ${ }^{5}$ Another study done between May 2011 to October 2012 in Saudi Arabia reported significant improvement in diabetes state after six months of the diabetes education program in patients about healthy diet, physical exercise, self-management of blood glucose level, $\mathrm{HbA}_{1 \mathrm{c}}$, patient medication complain and depression. ${ }^{6}$ Employment of education programs for type 2 diabetic patients is linked with best outcomes for example their dietary plan, physical exercise, commitment to medication, self-management blood glucose, $\mathrm{HbA}_{1 \mathrm{c}}$ and depression. ${ }^{6}$ Current practice in the management of patients with type 2 diabetes mellitus in Saudi Arabia was published in Dec 2009. ${ }^{7}$ Large number of patients did not reach the recommended target glycemic level. This indicates the existence of a gap among recommendations of the international guidelines and the factual practices. ${ }^{7}$ As per the reports there are no studies conducted evaluating how diabetic patient manage and store their medications during
Hajj. So, the aim of this study was to evaluate the awareness about symptoms of diabetes and dealing with those symptoms, management and storage of drug especially for the heat sensitive hormone (insulin) by diabetic patients participating in Hajj and the residents of Makkah and the facilities available for storage of medicines in particular insulin.

\section{METHODS Study design}

The cross-sectional study was conducted among the diabetic patients in the Al Mashaer during haj and the residents of Makkah to assess how they manage and store their medications in particular insulin. Prior approval was taken from the institutional ethical committee of Ibn Sina National College for conducting the study. The total number of participants were 459 diabetics of either sex above 50 years of age using insulin out of which 104 were Haij pilgrims and rest residents of Makkah. Patients were selected randomly from those attending the Hajj institutions in Al-Mashaer. Typed questionnaires were administered and verbal interview was conducted among 104 patients performing Hajj (64 patients in $\mathrm{Al}$ Mashaer and 40 in the hospital). Electronic survey was conducted among 355 diabetics residing in Makkah. Participants were asked to provide information about their age and if they use insulin or not. The eligible participants were requested to show their available documents related to diabetic therapies for review. The demographic data and medical history were documented Continuous variables were described how diabetics self-manage their medication, store insulin or oral hypoglycemic medication, their diet, awareness about symptoms of hyperglycemia, hypoglycemia, coma state and how to deal with these symptoms.

\section{Collection of Data}

The data collection was done from 24/9/2015 to $26 / 9 / 2015$ by verbal interview for 50 cases in Al-Mashaer, from 9/12 to $11 / 12 / 2015$ for 30 cases in $\mathrm{Al}$ Noor Hospitals and 24 cases in Al Harass Hospital, out of these 50 were outpatients and rest inpatient. Data from 355 cases were collected through electronic questionnaire on $07 / 11 / 2015$.

\section{Tool for the study}

The questionnaire was used as the tool for the study to evaluate the way the diabetic deal and store his medicine. The questionnaire has two parts, first part about the personal information such as (sex, age, literacy, the extent of using insulin), the second part has 11 Multiple Choice Questions concerning the present study. 


\section{Statistical Methods}

Collected data were tabulated and analyzed MannWhitney test was conducted on the data using SPSS v.21 statistical software.

\section{RESULTS AND DISCUSSION}

The response of the participants from residents of Makkah and the pilgrims of hajj are given in Table 1 and 2 respectively. The response of the participants from Makkah to various questions are as follows. $80.2 \%$ of Members from Makkah and 52.9\% pilgrim use insulin pen. $19.8 \%$ residents of Makkah and $11.5 \%$ pilgrims use Vial. $73.2 \%$ Makkah participants and $87.5 \%$ pilgrims have adequate quantity of insulin. 94\% Makkah participants and $57.7 \%$ pilgrims store insulin in cool place. $37.7 \%$ Makkah participants and 29.8\% pilgrims have mobile cooling portfolio. 49.4\% Makkah participants and $30.8 \%$ pilgrims check blood sugar before taking the dose of insulin. $69.9 \%$ of Makkah participants and 54.8\% pilgrims change the site of injection periodically. $74.9 \%$ of Makkah participants and $80.8 \%$ pilgrims stick to the time of administration. $48.6 \%$ of Makkah participants and $46.2 \%$ pilgrims understand the importance of diet to control diabetes. $72.1 \%$ of Makkah participants and $68.3 \%$ pilgrims are aware of the Symptoms of hyperglycemia. 67.6\% Makah participants and 68.3\% pilgrims know the symptoms of low blood sugar out of which $62.5 \%$ Makkah participants and $85.6 \%$ pilgrims have the knowledge to deal with low blood sugar.

\section{Statistical Analysis}

Mann-Whitney test (Table 3) was used to test the Ho the null hypothesis considering that there is statistically significant relationship between residents of Makkah and Hajjaj pilgrims about storage of insulin in cold place, practice of healthy diet, awareness about symptoms and management of hypoglycemia. Regarding the storage of insulin, the $z$ - value equals (-1.173) and it is less than the tabular value and the value of Sig. (0.241) and it is larger

\begin{tabular}{|c|c|c|c|c|c|}
\hline No. & The question & Choices & Frequency & Percent & $\begin{array}{c}\text { Valid } \\
\text { Percent }\end{array}$ \\
\hline \multirow{3}{*}{1} & \multirow{3}{*}{ Type of insulin } & Pen & 130 & 36.6 & 80.2 \\
\hline & & Vial & 32 & 9.0 & 19.8 \\
\hline & & Missing & 193 & 54.4 & - \\
\hline \multirow{3}{*}{2} & \multirow{3}{*}{$\begin{array}{l}\text { Do you have adequate } \\
\text { quantity }\end{array}$} & Yes & 213 & 60.0 & 73.2 \\
\hline & & No & 78 & 22.0 & 26.8 \\
\hline & & Missing & 64 & 18.0 & - \\
\hline \multirow{3}{*}{3} & \multirow{3}{*}{ Do you store it in a cool place } & Yes & 156 & 43.9 & 94.0 \\
\hline & & No & 10 & 2.8 & 6.0 \\
\hline & & Missing & 189 & 53.2 & - \\
\hline \multirow{3}{*}{4} & \multirow{3}{*}{$\begin{array}{l}\text { Do you have mobile cooling } \\
\text { bag }\end{array}$} & Yes & 61 & 17.2 & 37.7 \\
\hline & & No & 101 & 28.5 & 62.3 \\
\hline & & Missing & 162 & 45.6 & - \\
\hline \multirow{3}{*}{5} & \multirow{3}{*}{$\begin{array}{l}\text { Do you make glucose blood } \\
\text { test before you take your } \\
\text { insulin }\end{array}$} & Yes & 78 & 22.0 & 49.4 \\
\hline & & No & 80 & 22.5 & 50.6 \\
\hline & & Missing & 197 & 55.5 & - \\
\hline \multirow{3}{*}{6} & \multirow{3}{*}{$\begin{array}{l}\text { Do you change place of } \\
\text { injection routinely }\end{array}$} & Yes & 114 & 32.1 & 69.9 \\
\hline & & No & 49 & 13.8 & 30.1 \\
\hline & & Missing & 192 & 54.1 & - \\
\hline \multirow{3}{*}{7} & \multirow{3}{*}{$\begin{array}{c}\text { Do you take your medication } \\
\text { on time }\end{array}$} & Yes & 179 & 50.4 & 74.9 \\
\hline & & No & 60 & 16.9 & 25.1 \\
\hline & & Missing & 116 & 32.7 & - \\
\hline \multirow{3}{*}{8} & \multirow{3}{*}{ Do you eat healthy diet } & Yes & 85 & 23.9 & 48.6 \\
\hline & & No & 90 & 25.4 & 51.4 \\
\hline & & Missing & 180 & 50.7 & - \\
\hline \multirow{2}{*}{9} & \multirow{2}{*}{$\begin{array}{l}\text { Do you know symptoms of } \\
\text { hyperglycemia }\end{array}$} & Yes & 256 & 72.1 & 72.1 \\
\hline & & No & 99 & 27.9 & 27.9 \\
\hline \multirow{2}{*}{10} & \multirow{2}{*}{$\begin{array}{c}\text { Do you know symptoms of } \\
\text { hypoglycemia }\end{array}$} & Yes & 240 & 67.6 & 67.6 \\
\hline & & No & 115 & 32.4 & 32.4 \\
\hline \multirow[b]{2}{*}{11} & \multirow{2}{*}{$\begin{array}{c}\text { Do you know how manage } \\
\text { yourself if you have } \\
\text { hypoglycemia }\end{array}$} & Yes & 222 & 62.5 & 62.5 \\
\hline & & No & 133 & 37.5 & 37.5 \\
\hline \multicolumn{3}{|c|}{ Total } & 355 & 100.0 & 100.0 \\
\hline
\end{tabular}


than level of significance $5 \%$, favoring null hypothesis which assumes that there is no relation between Makkah and Hajjaj pilgrims in storage of insulin in a cool place. It can be assumed that the participants from both section are aware of the fact the storage condition for insulin is between $2-14^{\circ} \mathrm{C}$ and storage above this temperature breaks down the insulin affecting its potency. Regarding the practice of taking healthy diet the $z$-value equals $(-0.167)$ and it is less than the tabular value and the value of Sig.(0.867) and it is larger than level of significance $5 \%$, then we accept null hypothesis which assumes that there is no relation between Makkah and Hajjaj pilgrims in following healthy food system. It can be assumed that the level of awareness and practice of healthy diet

Table 2: Response of the participants from Haj pilgrim to the questionnaire asked.

\begin{tabular}{|c|c|c|c|c|c|}
\hline No. & The question & Choices & Frequency & Percent & $\begin{array}{l}\text { Valid } \\
\text { Percent }\end{array}$ \\
\hline \multirow{3}{*}{1} & \multirow{3}{*}{ Type of insulin } & Pen & 55 & 52.9 & 82.1 \\
\hline & & Vial & 12 & 11.5 & 17.9 \\
\hline & & Missing & 37 & 35.6 & \\
\hline \multirow{3}{*}{2} & \multirow{3}{*}{ Do you have adequate quantity } & Yes & 91 & 87.5 & 91.0 \\
\hline & & No & 9 & 8.7 & 9.0 \\
\hline & & Missing & 4 & 3.8 & \\
\hline \multirow{3}{*}{3} & \multirow{3}{*}{ Do you store it in a cool place } & Yes & 60 & 57.7 & 89.6 \\
\hline & & No & 7 & 6.7 & 10.4 \\
\hline & & Missing & 37 & 35.6 & \\
\hline \multirow{3}{*}{4} & \multirow{3}{*}{ Do you have mobile cooling bag } & Yes & 31 & 29.8 & 44.3 \\
\hline & & No & 39 & 37.5 & 55.7 \\
\hline & & Missing & 34 & 32.7 & \\
\hline \multirow{3}{*}{5} & \multirow{3}{*}{$\begin{array}{l}\text { Do you make glucose blood test } \\
\text { before you take your insulin }\end{array}$} & Yes & 32 & 30.8 & 32.3 \\
\hline & & No & 67 & 64.4 & 67.7 \\
\hline & & Missing & 5 & 4.8 & \\
\hline \multirow{3}{*}{6} & \multirow{3}{*}{$\begin{array}{l}\text { Do you change place of injection } \\
\text { routinely }\end{array}$} & Yes & 57 & 54.8 & 82.6 \\
\hline & & No & 12 & 11.5 & 17.4 \\
\hline & & Missing & 35 & 33.7 & \\
\hline \multirow{3}{*}{7} & \multirow{3}{*}{$\begin{array}{l}\text { Do you take your medication on } \\
\text { time }\end{array}$} & Yes & 84 & 80.8 & 83.2 \\
\hline & & No & 17 & 16.3 & 16.8 \\
\hline & & Missing & 3 & 2.9 & \\
\hline \multirow{3}{*}{8} & \multirow{3}{*}{ Do you eat healthy diet } & Yes & 48 & 46.2 & 47.5 \\
\hline & & No & 53 & 51.0 & 52.5 \\
\hline & & Missing & 3 & 2.9 & \\
\hline \multirow{3}{*}{9} & \multirow{3}{*}{$\begin{array}{c}\text { Do you know symptoms of } \\
\text { hyperglycemia }\end{array}$} & Yes & 80 & 76.9 & 78.4 \\
\hline & & No & 22 & 21.2 & 21.6 \\
\hline & & Missing & 2 & 1.9 & \\
\hline \multirow{3}{*}{10} & \multirow{3}{*}{$\begin{array}{c}\text { Do you know symptoms of } \\
\text { hypoglycemia }\end{array}$} & Yes & 71 & 68.3 & 68.9 \\
\hline & & No & 32 & 30.8 & 31.1 \\
\hline & & Missing & 1 & 1.0 & \\
\hline \multirow{3}{*}{11} & \multirow{3}{*}{$\begin{array}{l}\text { Do you know how manage } \\
\text { yourself if you have hypoglycemia }\end{array}$} & Yes & 89 & 85.6 & 86.4 \\
\hline & & No & 14 & 13.5 & 13.6 \\
\hline & & Missing & 1 & 1.0 & \\
\hline & Total & & 104 & 100.0 & 100.0 \\
\hline
\end{tabular}

\section{Table 3: The result of Mann-Whitney test.}

\begin{tabular}{|c|c|c|c|c|c|c|}
\hline Question & Group & Mean Rank & $\begin{array}{l}\text { Sum of } \\
\text { Ranks }\end{array}$ & $\begin{array}{c}\text { Mann- } \\
\text { Whitney }\end{array}$ & $\mathbf{Z}$ & $\begin{array}{l}\text { Asymp. } \\
\text { Sig. }\end{array}$ \\
\hline \multirow{2}{*}{$\begin{array}{c}\text { Do you store it in a cool } \\
\text { place? }\end{array}$} & Pilgrims & 120.67 & 8085.00 & \multirow[b]{2}{*}{5315.000} & \multirow[b]{2}{*}{-1.173} & \multirow[b]{2}{*}{.241} \\
\hline & Makkah sample & 115.52 & 19176.0 & & & \\
\hline \multirow{2}{*}{ Do you eat healthy diet? } & Pilgrims & 139.42 & 14081.00 & \multirow{2}{*}{8745.000} & \multirow{2}{*}{-0.167} & \multirow{2}{*}{.867} \\
\hline & Makkah sample & 137.97 & 24145.00 & & & \\
\hline \multirow{2}{*}{$\begin{array}{c}\text { Do you know symptoms } \\
\text { of hypoglycemia? }\end{array}$} & Pilgrims & 227.15 & 23396.00 & \multirow[b]{2}{*}{18040.00} & \multirow[b]{2}{*}{-0.254} & \multirow[b]{2}{*}{.800} \\
\hline & Makkah sample & 230.18 & 81715.00 & & & \\
\hline \multirow{2}{*}{$\begin{array}{c}\text { Do you know how } \\
\text { manage yourself if you } \\
\text { have hypoglycemia? }\end{array}$} & Pilgrims & 187.13 & 19274.00 & \multirow[b]{2}{*}{13918.00} & \multirow[b]{2}{*}{-4.564} & \multirow[b]{2}{*}{$.000^{*}$} \\
\hline & Makkah sample & 241.79 & 85837.00 & & & \\
\hline
\end{tabular}


concerning diabetes is similar between both the sections. About the symptoms of low blood sugar level the zvalue equals $(-0.254)$ and it is less than the tabular value and the value of Sig. (0.800) and it is larger than level of significance $5 \%$, then we accept null hypothesis which assumes that there are no differences between Makkah and Hajjaj pilgrims in their awareness of low blood sugar symptoms. For the question about the knowledge to deal with the symptoms of low blood sugar the $\mathrm{z}$ value equals (-4.564) and it is larger than the tabular value and the value of Sig. (0.000) and it is less than level of significance $5 \%$, then we refuse null hypothesis and accept the alternative that assumes that there is a difference between diabetic Makkah and Hajjaj pilgrims in their knowledge about dealing with low blood sugar symptoms. May be due to cultural and social differences also the symptoms of diabetes are different from one to another, one of these symptoms is coma which is due to inappropriate use of diabetes medicines and not following of healthy diet, which causes the blood sugar to be less than $60 \mathrm{mg} / 100 \mathrm{ml}$ of blood and that leads to the coma. There are no refrigerators available for storing insulin in the Red Crescent also most of them don't have mobile coolers to suit their move through Al Mashaer. The diabetics don't do blood sugar test regularly.

\section{CONCLUSION}

There are no differences between Makkah and Hajjaj pilgrims regarding saving insulin in a cold place, following healthy food system and in their awareness of low blood sugar symptoms. While, there is a difference between diabetic Makkah and Hajjaj diabetic pilgrims in their knowledge about dealing with low blood sugar symptoms. Also there is no suitable places to save insulin (refrigerators) in the Red Crescent and they have no mobile coolers to suit their move through Al-Mashaer. The diabetics don't check blood sugar.

\section{Recommendation}

Provision should be made for the supply refrigerators for storing thermo labile medicines in Al Mashaer. There are reports about the use of Jeer (Semi porous earthen pot) for effective storage of insulin, which can also be employed as an alternative to refrigerator. ${ }^{8}$ Educating pilgrims about the importance of having healthy food.
Training courses should be conducted for the diabetics to make them aware of dealing with their chronic disease. Making brochures about dealing with low or high blood sugar, about the symptoms of this disease should be distributed to the pilgrims in Al Mashaer.

\section{Future work}

The researcher suggests more studies about the ways of storing insulin and the availability of health care in Hajj institutions.

\section{ACKNOWLEDGEMENT}

We hereby express our sincere gratitude to all the participants, hospitals and statistician for their help in completing this work.

\section{CONFLICT OF INTEREST}

The authors declare that there is no conflict of interest.

\section{ABBREVIATIONS}

$\mathbf{H b A}_{1 \mathrm{c}}$ : Glycated haemoglobin.

\section{REFERENCES}

1. Siavash M, Haghighi S. Recommendations for patients with diabetes mellitus during hajj pilgrimage. J Res Med Sci. 2012;17:988-9.

2. Beshyah SA, Sherif IH. Care for People with Diabetes during The Moslem Pilgrimage (Haj) An Overview. Libyan J Med. 2008;3(1):39-41.

3. Hala A, Wendy G, Ateeq S. Diabetes care during Hajj. Clinical Medicine. 2011;11:218-21.

4. Mohd AG, Satish K, Hilal AR, Bashir AL, Abdul HZ. Hyperglycemic emergencies in Indian patients with diabetes mellitus on pilgrimage to Amarnathji yatra. Ind J of Endocrin Meta. 2012;16(7):87-90.

5. Al-Rubeaan KA, Al-Manaa HA, Khoja TA, Al-Sharqawi AH, Youssef AM, Alotaibi MS, et al. Health care services provided to type 1 and type 2 diabetic patients in Saudi Arabia. Saudi Med J. 2015;36(10):1216-56.

6. Al-Hayek AA, Robert AA, Al-Dawish MA, Zamzami MM, Sam AE, Alzaid AA. Impact of an education program on patient anxiety, depression, glycemic control and adherence to self-care and medication in Type 2 diabetes. J. Family Community Med. 2013;20(2):77-82.

7. Al-Elq $\mathrm{AH}$. Current practice in the management of patients with type 2 diabetes mellitus in Saudi Arabia. Saudi Med J. 2009;30(12):1551-6.

8. Khiriah AS, Waffa F, Najla S, Muneera AS, Munirah ATI, Adnan A, et al. Storing insulin in a clay pot in the desert causes no loss of activity: A preliminary report. Annals of Saudi Med. 1999;19(6):547-549 
PICTORIAL ABSTRACT

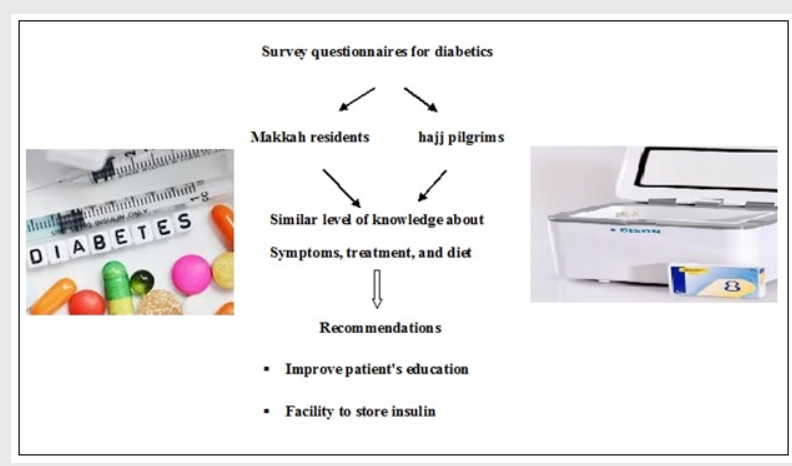

\section{SUMMARY}

The present work as a cross sectional survey among the diabetic patients performing Hajj and residents of Makkah to evaluate their awareness about storage of insulin and symptoms of hypo/hyper glycemic conditions. The study revealed that there are no differences between Makkah and Hajjaj pilgrims regarding saving insulin in a cold place, following healthy food system and in their awareness of low blood sugar symptoms. While, there is a difference between diabetic Makkah and Hajjaj diabetic pilgrims in their knowledge about dealing with low blood sugar symptoms. Also there is no suitable places to save insulin (refrigerators) in the Red Crescent and they have no mobile coolers to suit their move through AlMashaer. The diabetics don't check blood sugar. We do hereby recommend on imparting education to the diabetics about the importance of storage of insulin, dealing with hypo/hyper glycemic conditions and diet.

\section{About Authors}

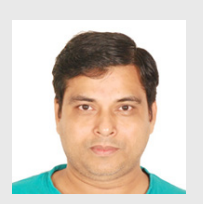

Dr. Dibya Sundar Panda, Assistant Professor, Jouf University, KSA. 20 years of teaching and research experience in India and Kingdom of Saudi Arabia. Research area: Development of drug delivery systems, Exploring pharmaceutical application of natural gums.

Dr. Mohamed Gamal, Assistant Professor, Jouf University, KSA. 7 years of teaching and research experience in Egypt and Kingdom of Saudi Arabia. Research area: Analytical method development.

Cite this article: Othman K, Khan AAL, Iqubal SMS, Mohammed T, Maqbul MS, Gamal M, Al-Sanea MM, Elmowafy M, Shalaby K, Panda DS, Alghamdi S. Assessment of Knowledge of Diabetic Patients about Glycemic Abnormalities and Medicine Storage in Makkah during Hajj Pilgrimage. Indian J of Pharmaceutical Education and Research. 2020;54(3s):s716-s721. 